\title{
Gravel Quarries Could Affect Vimba Bream (Vimba vimba Linnaeus 1758) Populations from Someș River, Romania
}

\author{
Tudor PĂPUC ${ }^{1,2 *}$
}

\author{
${ }^{1}$ Faculty of Animal Science and Biotechnologies, University of Agricultural Sciences and Veterinary Medicine Cluj- \\ Napoca, 3-5 Mănăștur St., 400372, Romania \\ ${ }^{2}$ Bioflux SRL, 54 Ceahlău St., Cluj-Napoca 400488, Romania \\ *Corresponding author: T. Păpuce-mail: tudor.papuc@usamvcluj.ro
}

RESEARCH ARTICLE

\begin{abstract}
The European stocks of vimba bream (Vimba vimba) are presently declining, having a "vulnerable" status in some countries. In Romania, there is a lack of scientific studies regarding the species. In order to supplement existing information about this species, specimens of vimba bream were collected from the middle sector of Someș River (Transylvania). Age, length and weight were recorded from 4 sampling points, near gravel quarries. The results show that only young specimens were found. The highest total length value was $22.77 \mathrm{~cm}$, while the highest weight recorded was $121.08 \mathrm{~g}$. Most vimba bream were captured in the first location, where less anthropogenic pressure exists. The populations are in decline in this region because of gravel quarries, among other factors.
\end{abstract}

Keywords: anthropogenic change; condition factor; mining; substrate; total length.

Received: 04 September 2020 Accepted: 22 March 2021

Published: 15 May 2021

DOI:

10.15835/buasvmcn-asb:2020.0018

\section{INTRODUCTION}

The vimba bream (Vimba vimba) is a medium size fish, from the Cyprinidae family, being the only representative of the Vimba genus in Romania. Unfortunately, the European populations of vimba bream are continuously decreasing, the species being endangered in some countries (Austria, Czech Republic, Poland, Finland). The decline has a number of causes, including the degradation of natural habitats (Naderi et al., 2004), barriers preventing upstream migrations (Jurvelius and Auvinen, 2001), or intensive fishing (Cocan and Mireșan, 2018). Artificial reproduction and rearing can present some solutions for the current decline and efforts are made to remediate the situation (Myszkowski et al., 2006; Kwasek et al., 2009; Okgerman et al., 2011; Lepič et al., 2019) and more studies regarding the evolution of vimba bream populations in Europe are conducted (Czerniejewski et al., 2011).

In Romania, the fish is seen as a coarse fish, without any economic importance. When caught, it enters the "other species" category (Oțel, 2007). However, the fish was at one point one of the most appreciated cyprinids (Bănărescu, 1964), probably because the flavor is influenced by the higher content of fat. The vimba bream is a highly appreciated fish species by most anglers and it is considered a species with a high economic value in other countries (Wiśniewolski, 1987).

V. vimba is closely related to fish from the genera Abramis and Blicca. The fish has a medium size, with a laterally compressed, fairly long body (Bănărescu, 1964). The fleshy long snout ends in a sub-terminal mouth, with thin lips. The average length is $25-30 \mathrm{~cm}$, but it can exceptionally reach $50 \mathrm{~cm}$, exceeding $1 \mathrm{~kg}$ (Oțel, 2007). The dorsal color varies from gray towards blue or green, while the 
flanks and abdomen are white. It can live up to 17 years (Cocan, and Mireșan, 2018).

The vimba bream is distributed in the rivers draining in the Black Sea, Caspian Sea, Baltic Sea and North Sea, but also in some lakes (fishbase.se). For example, some specimens were found in Geaca pond, Cluj County, Romania, the pond communicating with a nearby river (personal observation), or Lake Ostrowieckie, Poland (Hliwa and Martyniak, 2002). It was introduced in France, Netherlands and Russia (Ermolin and Shashulovskii, 2006). In Romania, the fish is present in most main rivers and their tributaries, excluding high altitude rivers. It can be found in high numbers from rhithral to potomal waters. It can be found in the Danube, and, sometimes, in the Danue Delta and littoral lakes (Oțel, 2007).

The fish is reophilic, but some authors observe the preference of the vimba bream for brackish water (Cocan and Mireșan, 2018). It inhabits the deeper parts of rivers, with hard substrate, like gravel or sand (Hudson et al., 2014). The vimba bream is omnivorous, feeding on algae, detritus, worms, mollusks, and even small fish (Bănărescu, 1964). They reach sexual maturity after 3-7 years, being a late maturing species and perform short-distance migrations for spawning (Hudson et al., 2014). The brackish water and lake populations migrate to fast flowing rivers (Freyhof and Kottelat, 2007). The spawning takes place in April-May, at temperatures between $14-19^{\circ} \mathrm{C}$ (Cocan and Mireșan, 2018). The spawning migrations start in September, stop in winter, and start again in early spring (Bănărescu, 1964; Freyhof and Kottelat, 2007; Tambets et al., 2018). During spawning, the sexual dimorphism is visible, males presenting sexual ornamentations consisting of breeding tubercles on the head and dorsal area, as well as a darkened color. A difference visible throughout the year is the length of the paired fins, which are slightly longer for males than for females (Oțel, 2007). The reproductive characteristics vary depending on age, location, environmental conditions, and other factors (Patimar and Safari, 2010).

The aim of this study was to present a factor that can produce the population decline of vimba bream, in-stream mining, and some morphological characteristics of the vimba bream from Someș River, Romania.

\section{MATERIALS AND METHODS}

The study was conducted from June to July 2020, in 4 sampling points from the middle sector of Someș River, on a river length of approximately $11 \mathrm{~km}$, Sălaj County, Romania. The 4 sampling points were selected based on their proximity to gravel pits or quarries, where the substrate of the river changed in the last years. Moreover, the environmental parameters had been suitable for vimba bream in previous years and the sector is more accessible. The sampling points are near Lemniu, Letca, Cuciulat and Băbeni villages (Figure 1). Each sampling point was sampled for 3 days, using angling techniques: feeder fishing, with different ground baits to attract the fish, especially cheese flavored for nase (Chondrostoma nasus) and vimba bream, and mostly earthworm and fly maggots as hook baits. One feeder rod was used without ground bait, only with hook bait, as a control, to check the efficiency of the ground bait. The leader distance (distance between feeder and hook) varied between 40 and $70 \mathrm{~cm}$. Ground bait was continuously administered with feeders of 45 to $65 \mathrm{~g}$, at casting intervals of 5 to 10 minutes. Angling techniques are often used in fish sampling, since they are less invasive and facilitate the selection of fish (Hetrick and Bromaghin, 2004).

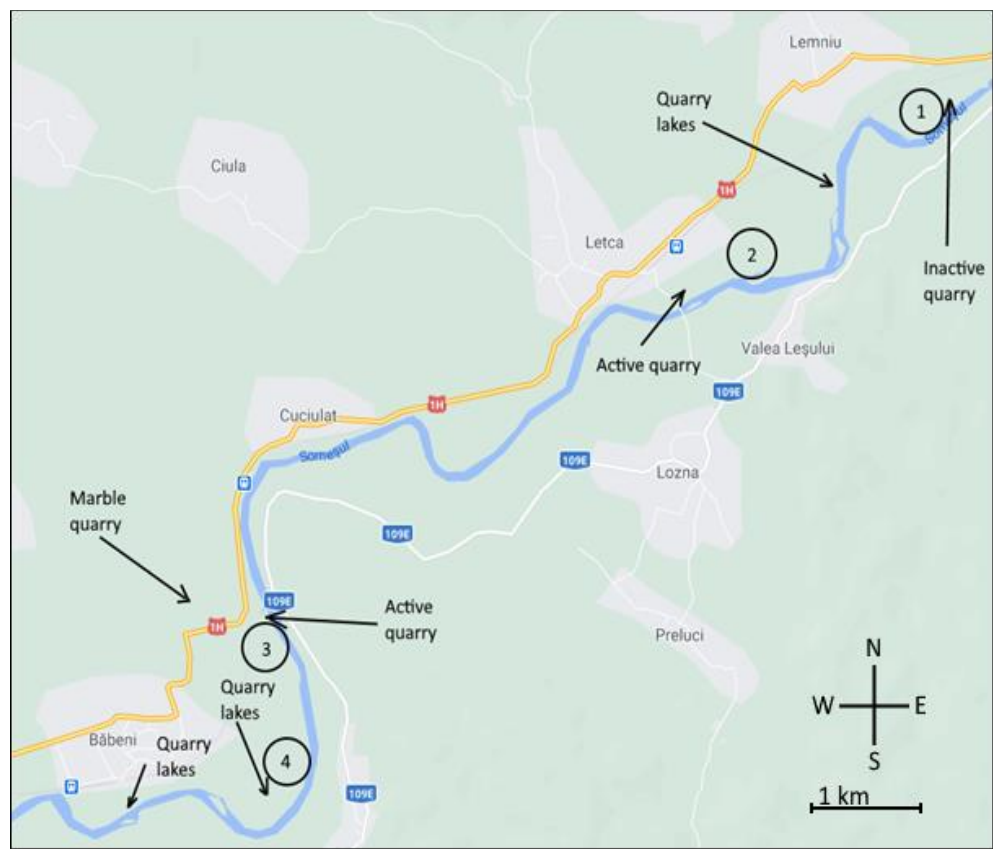

Figure 1. Sampling locations (1 - Lemniu; 2 - Letca; 3 - Cuciulat; 4 - Băbeni). 
The vimba specimens captured were weighted using a small digital scale (model Yago TSC500) with a precision of $0.01 \mathrm{~g}$. The total length was determined using an electronic caliper. Age was determined by counting the scale growth rings. 2 scales were sampled from each vimba bream in small plastic containers with water, and transported to a nearby location where the determination was made using the Celestron Digital Microscope Pro. Other captured species were recorded. The Fulton condition index was determined using the following formula (Ricker, 1975): $\mathrm{K}=(\mathrm{BW} / \mathrm{TL} 3) \mathrm{x} 100$, where $\mathrm{K}$ is the Fulton index, BW is the body weight of the fish and TL is the total length.

The following environmental parameters were recorded: substrate type, flow speed, water temperature, turbidity. Some other observations regarding the environment were noted. The flowed speed was determined by timing the seconds in which a float was carried by the current for $1 \mathrm{~m}$. The temperature was determined using a water thermometer tied to a fishing line, and placed on the substrate, in the fishing place. Turbidity was recorded with a Secchi disk.

\section{RESULTS AND DISCUSSIONS}

The environmental parameters recorded are presented in Table 1 . Water turbidity was high, due to the previous heavy rainfalls. The best value was $20 \mathrm{~cm}$, recorded in sampling point 2 . Water temperature was between $19-20^{\circ} \mathrm{C}$, without big variations between sampling points. Flow speed and substrate type varied between sampling points, because the fishing locations had different conditions. The highest flow speed was $0.32 \mathrm{~m} / \mathrm{s}$, and the lowest was $0.08 \mathrm{~m} / \mathrm{s}$. The substrate varied from small gravel to mud, sand and bigger gravel, from sampling points 1 to 4 , respectively.

Table 1. Environmental observations from the 4 sampling locations

\begin{tabular}{cccccccc}
\hline $\begin{array}{c}\text { Sampling } \\
\text { point }\end{array}$ & Name & Coordinates & Substrate & $\begin{array}{c}\text { Flow } \\
\text { spee } \\
\mathbf{d}\end{array}$ & $\begin{array}{c}\text { Temperatur } \\
\mathbf{e}\end{array}$ & $\begin{array}{c}\text { Turbidit } \\
\mathbf{y}\end{array}$ & Observations \\
\hline $\mathbf{1}$ & Lemniu & $\begin{array}{c}47.347201 ; \\
23.497434\end{array}$ & $\begin{array}{c}\text { Small } \\
\text { gravel }\end{array}$ & $\begin{array}{c}0.27 \\
\mathrm{~m} / \mathrm{s}\end{array}$ & $19.7^{\circ} \mathrm{C}$ & $15 \mathrm{~cm}$ & $\begin{array}{c}\text { Former quarry. Inactive in } \\
\text { the last } 10 \text { years. }\end{array}$ \\
\hline $\mathbf{2}$ & Letca & $\begin{array}{c}47.335475 ; \\
23.472862\end{array}$ & $\begin{array}{c}\text { Mud and } \\
\text { gravel. }\end{array}$ & $\begin{array}{c}0.08 \\
\mathrm{~m} / \mathrm{s}\end{array}$ & $20^{\circ} \mathrm{C}$ & $12 \mathrm{~cm}$ & $\begin{array}{c}\text { Muddy substrate near the } \\
\text { shore. After } 15 \mathrm{~m} \text { there was } \\
\text { gravel. }\end{array}$ \\
\hline $\mathbf{3}$ & Cuciulat & $\begin{array}{l}47.308478 ; \\
23.418359\end{array}$ & Sand & $\begin{array}{c}0.32 \\
\mathrm{~m} / \mathrm{s}\end{array}$ & $19.8^{\circ} \mathrm{C}$ & $10 \mathrm{~cm}$ & $\begin{array}{c}\text { Leakage of muddy water } \\
\text { from the quarry into the } \\
\text { river. }\end{array}$ \\
\hline $\mathbf{4}$ & Băbeni & $\begin{array}{c}47.300387 ; \\
23.422184\end{array}$ & Big gravel & $\begin{array}{c}0.25 \\
\mathrm{~m} / \mathrm{s}\end{array}$ & $19.5^{\circ} \mathrm{C}$ & $13 \mathrm{~cm}$ & $\begin{array}{c}\text { In-stream mining could not } \\
\text { be conducted because a float } \\
\text { bridge is present. }\end{array}$ \\
\hline
\end{tabular}

Only 16 specimens of vimba bream were captured (Figure 2). The total length (TL), body weight (BW), age and condition factor are presented in Table 2.

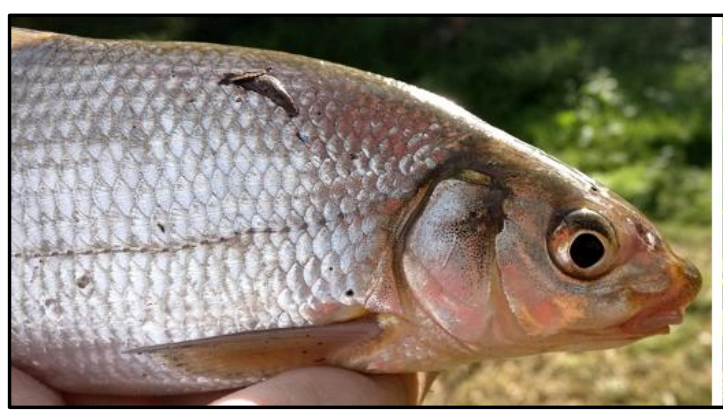

(a)

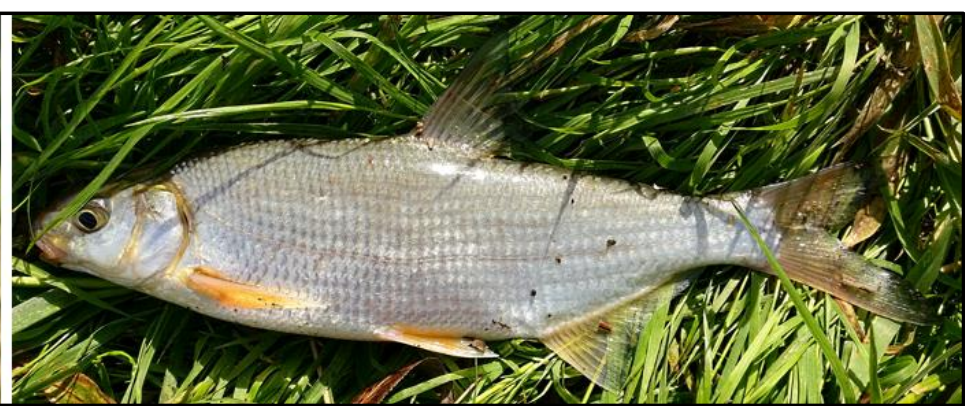

(b)

Figure 2. Vimba bream (Vimba vimba) from Someș River, Romania; (a) Lateral view head detail; (b) Lateral view. 
Table 2. Total length, body weight, sex, age and Fulton condition index values for vimba bream (Vimba vimba), Someș River

\begin{tabular}{|c|c|c|c|c|}
\hline $\begin{array}{c}\text { Location and number of } \\
\text { fish }\end{array}$ & TL (cm) & BW (g) & Age & Condition factor \\
\hline \multicolumn{5}{|l|}{ Lemniu } \\
\hline 1 & 14.30 & 41.32 & $1+$ & 1.41 \\
\hline 2 & 20.12 & 93.07 & $2+$ & 1.14 \\
\hline 3 & 22.69 & 121.08 & $3+$ & 1.03 \\
\hline 4 & 15.02 & 46.75 & $1+$ & 1.38 \\
\hline 5 & 20.32 & 84.45 & $2+$ & 1.00 \\
\hline 6 & 20.51 & 78.90 & $2+$ & 0.91 \\
\hline 7 & 20.93 & 91.33 & $2+$ & 0.99 \\
\hline 8 & 22.77 & 117.44 & $3+$ & 0.99 \\
\hline 9 & 20.98 & 96.39 & $2+$ & 1.04 \\
\hline \multicolumn{5}{|l|}{ Letca } \\
\hline 10 & 20.04 & 92.15 & $2+$ & 1.14 \\
\hline \multicolumn{5}{|l|}{ Cuciulat } \\
\hline 11 & 20.79 & 94.41 & $2+$ & 1.05 \\
\hline 12 & 14.78 & 45.26 & $1+$ & 1.4 \\
\hline \multicolumn{5}{|l|}{ Băbeni } \\
\hline 13 & 20.59 & 88.29 & $2+$ & 1.01 \\
\hline 14 & 20.60 & 90.90 & $2+$ & 1.03 \\
\hline 15 & 20.58 & 95.53 & $2+$ & 1.09 \\
\hline 16 & 13.95 & 36.32 & $1+$ & 1.34 \\
\hline
\end{tabular}

Note: TL - total length; BW - body weight.

The condition factor is close to 1 for age groups $2+$ and $3+$, while for age group $1+$, the Fulton condition index is very high, but similar to the results of another study from Timiș River, where the condition factor for small vimba bream was 1.44 (Stavrescu-Bedivan et al. 2017). One explanation could be that all 4 vimba breams from age group 1+ were full of the ground bait used to lure them, while the bigger vimba breams did not regurgitate any bait. It could be that bigger specimens are more cautious and select the better feed. As smaller specimens fed on both ground bait and hook bait, the larger specimens were attracted by the ground bait, but preferred to feed mostly on the hook bait (maggots and worms having a higher nutritional quality and being more attractive than the ground bait). No vimba bream was captured at the control rod, without ground bait.

The weight is lower for vimba bream with a length of $22 \mathrm{~cm}$ than the one observed by Hliwa and Martyniak (2002), with an average of $119.26 \mathrm{~g}$ and $202.1 \mathrm{~g}$, respectively. However, the fish in the study from 2002 were females weighed before spawning, with a high gonadosomatic index. Compared to the results of Okgerman et al. (2011), who studied the age weight relationships of vimba bream from a lake in Turkey, all age groups have a higher weight in the current study. The different results show that there is variety in the development of vimba bream throughout Europe.

In Lemniu, the first location, sampling collection took place near an old inactive gravel quarry. This sampling point produced the most vimba breams, 9 specimens, and had the best turbidity. The vimba breams presented a total length of $19.73 \pm 3.03 \mathrm{~cm}$ (mean $\pm \mathrm{SD}$ ), with minimum and maximum of 14.3 and $22.77 \mathrm{~cm}$. The weight was $85.63 \pm 27.37 \mathrm{~g}($ mean $\pm \mathrm{SD}$ ), with a minimum and maximum of 41.32 and $121.08 \mathrm{~g}$. Upstream from sampling point 1 , there are no active quarries or constructions impeding the migrations of vimba bream.

Sampling point 2 was in Letca, near an active gravel quarry. The substrate here suffered major changes in the last years. The gravel was slowly replaced by mud, and the depth decreased from 1.5-2 $\mathrm{m}$ to $0.5-1 \mathrm{~m}$ in the last years (personal observations). Gravel substrate was present, however, only after 15-20 m from the riverbank. The depth was less than $1 \mathrm{~m}$ there, and the only specimen captured from Letca was from gravel substrate. The fish was reported here in previous studies (Cocan et al., 2014).

Sampling point 3 was in an active quarry. In past years, other expeditions showed that the fish was present in larger numbers. Only 2 specimens were captured here. Although in a quarry, the substrate did not change in structure in the last years, remaining mostly sandy with some gravel. The depth was between 1 and $2 \mathrm{~m}$. This location had the highest turbidity, $10 \mathrm{~cm}$, mainly because the quarry released muddy water from gravel washing 
processes into the river. The fine particles of mud covered the substrate. A clear line was observable $10 \mathrm{~m}$ from the riverbank, from which the water was clearer. The muddy water leakage took place $100 \mathrm{~m}$ upstream from the fishing point. From time to time, the silt deposited in the river from the leakage is excavated (Figure 3).

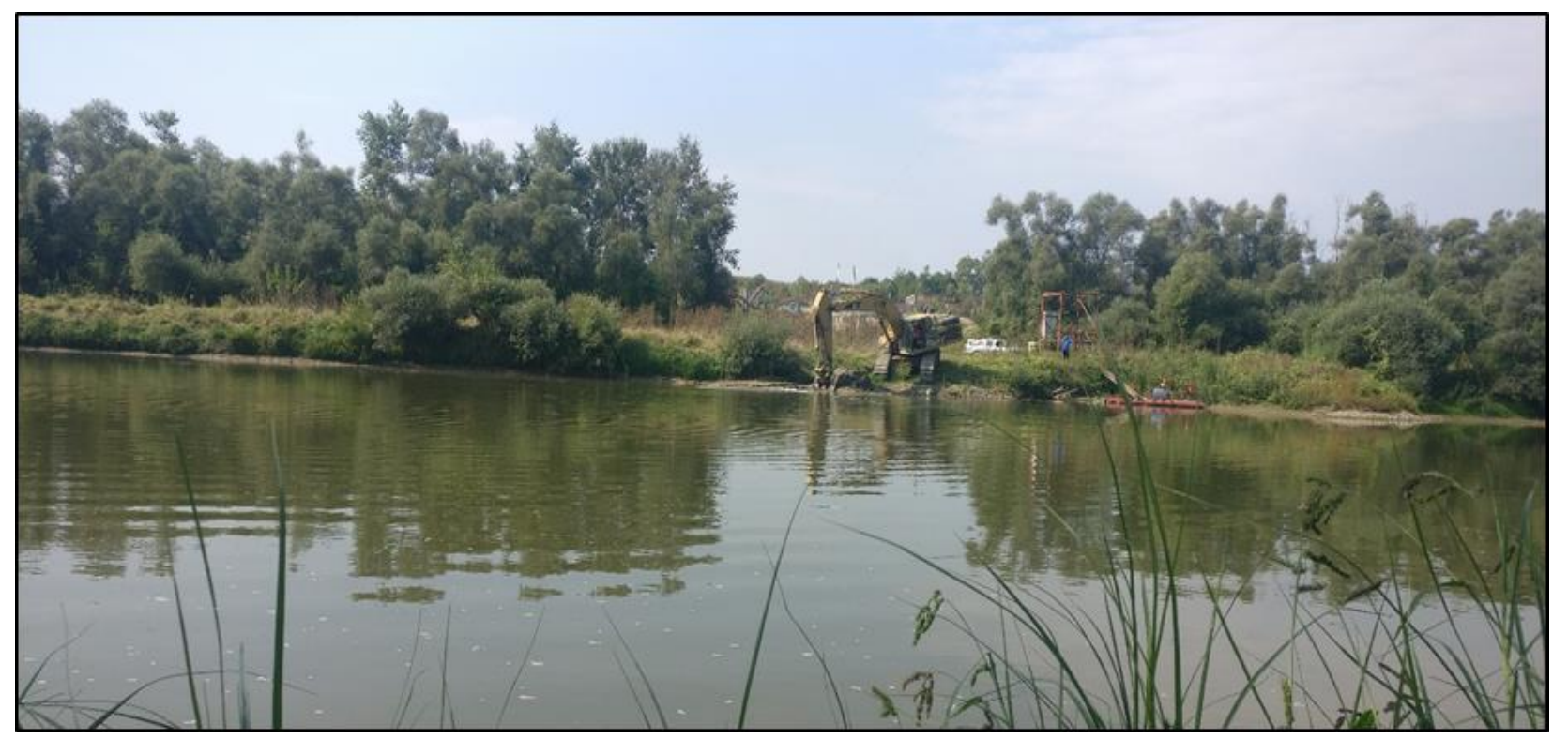

Figure 3. Silt deposits from quarry water leakage in Someș River being excavated in sampling point 3.

The last sampling point provided 4 vimba breams. The location is near a quarry lake. The water depth was $1.5 \mathrm{~m}$ on average, and the substrate consisted of big gravel and rocks, the river entering a sector characterized by rocks, stones and a higher depth. No in-stream mining took place here, because a float bridge exists, and a possible change of river course or substrate could be dangerous.

Gravel is important for the natural spawning of vimba bream (Hamackova et al., 2008). However, in all locations gravel was at one point extracted from the riverbed by gravel quarries for the construction industry. Gravel and sand extraction can change the riverbed composition and structure, can degrade water quality, can produce soil erosion, loss of biodiversity and other negative effects (Kelly et al., 2005; Padmalal et al., 2007; Kamboj and Kamboj, 2019). In the studied region, the quarries changed the river substrate structure, in some parts even the course of the river (locations 2 and 3), and made the riverbed less hospitable for vimba bream, but also for other species, like barbel (Barbus barbus). The water waste from gravel washing processes spilled in the river also affects fish. Silt covered the substrate, reducing invertebrate biodiversity, with further consequences in the trophic food chain. Due to this constant pressure, among other factors, some fish species populations are declining in this small river sector. This can be deduced from the high number of vimba bream captured in the first location, where the pressure was relieved after the quarry stopped its activity. In addition, no impending structures or quarries were found upstream from the first location.

Other fish were also captured, including: chub (Squalius cephalus) from all locations, bleak (Alburnus alburnus) from all locations, barbel (B. barbus) from locations 1, 3 and 4, spirlin (Alburnoides bipunctatus) from all locations, goby (Gobio gobio) from all locations, catfish (Silurus glanis) from locations 1 and 3, white-eye bream (Abramis sapa) from locations 1 and 2, and monkey goby (Neogobius fluviatilis) from all locations. Nase (C. nasus) was observed in locations 1, 3, and 4, doing its specific jumps, but was not captured. Asp (Aspius aspius) was observed in all 4 locations. However, the fish sampling was concentrated on vimba bream, so other species are not presented in detail in this study.

\section{CONCLUSIONS}

Vimba breams are scarce in the studied region (Someș River between Lemniu and Băbeni, Sălaj County, Romania). Only young specimens were found, but with a good condition factor. The decrease in populations could have occurred due to pressure from the many quarries in the area and because of changes in habitat. More investigations are required to clearly determine the relationship between quarry activity and fish population decline in Somes River. 
Author Contributions: The author performed all steps of the study.

Funding Source: There was no funding for this study.

\section{Acknowledgments}

This research did not receive any specific grant from funding agencies in the public, commercial, or not-for-profit sectors.

\section{Conflicts of Interest}

The author declares that he does not have any conflict of interest.

\section{REFERENCES}

1. Bănărescu P. Fauna of the People's Republic of Romania. Volume XIII, Pisces - Osteichthyes. Bucharest: The Publishing House of the Academy of People's Republic of Romania; c1964.

2. Cocan D, Mireșan V. Ichthyology. Volume I. Fish systematics and morphology. Cluj-Napoca: Colorama; c2018.

3. Cocan D, Mireșan V, Oțel V, Păpuc T, Lațiu C, Coșier V, et al. First record of the Pontian monkey goby Neogobius fluviatilis (Pallas, 1814) in the Someș River, Transylvania - Romania. ProEnvironment 2014; 7:240-46.

4. Czerniejewski P, Rybczyk A, Tanski A, Keszka S, Antoszek A. Growth rate and condition of vimba, Vimba vimba (Actinopterygii: Cypriniformes: Cyprinidae), a species under restitution in the Odra River estuary. Acta Ichthyol Piscat. 2011; 41(3):215-22.

5. Ermolin VP, Shashulovskii VA. On the results of Vimba vimba (Cypriniformes, Cyprinidae) introduction in the Volgograd Reservoir. J Ichthyol. 2006; 46(6):487-89.

6. Freyhof J, Kottelat M. Handbook of European freshwater fishes. Cornol: Publications Kottelat; c2007.

7. Hamackova J, Kozak P, Lepic P, Kouril J. Artificial reproduction and rearing hatching material Vimba bream. Vodnany: Research Institute of Fish Culture and Hydrobiology; c2008.

8. Hetrick NJ, Bromaghin JF. Sampling bias of hook-and-line gear used to capture rainbow trout in Gertrude Creek, Alaska. N Am J Fish Manag. 2004; 26(1):13-23.

9. Hliwa P, Martyniak A. The absolute fecundity of Vimba vimba (L.) from Lake Ostrowieckie (Oder River catchment area, northwest Poland). Arch Polish Fish. 2002; 10(2):269-74.

10. Hudson GA, Vonlanthen P, Seehausen O. Population structure, inbreeding and local adaptation within an endangered riverine specialist: the nase (Chondrostoma nasus). Conserv Genet. 2014; 15:933-51.

11. Jurvelius J, Auvinen H. Fish habitat science and management in Finnish freshwaters. Aquat Ecosyst Health \& Manag. 2001; 4(4):413-21.

12. Kamboj N, Kamboj V. Water quality assessment using overall index of pollution in riverbed-mining area of Ganga-River Haridwar, India. Water Sci. 2019; 33(1):65-74.

13. Kelly D, McKerchar A, Hicks M. Making concrete: ecological implications of gravel extraction in New Zealand $\begin{array}{lllll}\text { rivers. Water } \quad \text { \& } & \text { Atmosphere. }\end{array}$ https://niwa.co.nz/sites/niwa.co.nz/files/import/attachments/concrete.pdf.

14. Kwasek K, Zhang Y, Hliwa P, Gomulka P, Ostaszewska T, Dabrowski K. Free amino acids as indicators of nutritional status of silver bream (Vimba vimba), when using commercial and purified diets. Comp Biochem Physiol Part A Mol Integr Physiol. 2009; 153:113-19.

15. Lepič P, Blecha M, Kozák P. Intensive winter culture of Chondrostoma nasus (Linnaeus, 1758) and Vimba vimba (Linnaeus, 1758) for spring restocking. Turk J Fish Aquat Sci. 2019; 20(2):97-102.

16. Myszkowski L, Kamiński R, Kamler E. Compensatory growth and matter or energy deposition in Vimba vimba juveniles fed natural food or a formulated diet. Folia Zool. 2006; 55(2):211-22.

17. Naderi M, Abdoli A. Fish species atlas of south Caspian Sea basin (Iranian waters). Teheran: Iranian Fisheries Research Organization; c2004.

18. Okgerman H, Elp M, Yardimci CH. Growth, the length-weight relationship, and reproduction in vimba (Vimba vimba L. 1758) sampled from an oligo-mesotrophic lake in northwest Anatolia (Turkey). Turk J Zool. 2011; 35(1):87-96.

19. Oțel V. Danube Delta Biosphere Reservation fish atlas. Tulcea: Danube Delta Technological Information Center; c2007. 
20. Padmalal D, Maya K, Sreebha S, Sreeja R. Environmental effects of river sand mining: a case from the river catchments of Vembanad lake, southwest coast of India. Environ Geol. 2007; 54:879-89.

21. Patimar R, Safari S. Description of the biology of Caspian vimba, Vimba vimba (Linnaeus, 1758), in Gorgan BayMiankaleh Wildlife Refuge (southeast Caspian Sea). Chin J Oceanol Limn. 2010; 28(6):1173-79.

22. Ricker WE. Computation and interpretation of biological statistics of fish populations. Ottawa: Bulletin 191 of the Fisheries Research Board of Canada; c1975.

23. Stavrescu Bedivan M, Aioanei FT, Scaeteanu GV. Length-weight relationships and condition factor of 11 fish species from the Timiș River, western Romania. Agric. \& For. 2017; 63(4):281-85.

24. Wiśniewolski W. Catches of fish in Vistula, Oder and Warta rivers in 1953-1978. Rocz Nauk Rol H. 1987; 101:71114.

25. https://www.fishbase.se/summary/Vimba-vimba.html. Lastly accessed on: 25 February 2021. 